\title{
Matrine induces the hepatic differentiation of WB-F344 rat hepatic progenitor cells and inhibits Jagged 1/HES1 signaling
}

\author{
ZHIYUN YANG, LI WANG and XIANBO WANG \\ Department of Traditional Chinese Medicine, Beijing Ditan Hospital, Capital Medical University, \\ Beijing 100015, P.R. China
}

Received July 16, 2015; Accepted July 13, 2016

DOI: $10.3892 / \mathrm{mmr} .2016 .5668$

\begin{abstract}
Matrine is a Chinese medicine, which is widely utilized for the attenuation of liver injuries and promotion of liver regeneration. It was previously observed that the in vivo administration of matrine promoted oval cell-mediated liver regeneration in a rat model, suggesting that this compound may affect the differentiation of hepatic progenitor cells. The present study aimed to determine the mechanisms underlying this observation and to investigate the effect of matrine on the differentiation of the WB-F344 rat hepatic progenitor cell line. Matrine was administered to rats, and rat serum was collected. WB-F344 cells were cultured in the presence or absence of the rat serum for 24-72 $\mathrm{h}$, and the effects on cell viability and proliferation were assessed using acridine orange/propidium iodide staining and a 3-(4,5-dimethylthiazol-2-yl) -2,5-diphenyltetrazolium bromide assay. The expression of albumin (ALB, a hepatocyte marker) and the notch signaling pathway ligand, Jagged 1, were assessed using immunohistochemistry and western blotting, and the mRNA transcription of ALB, Jagged 1 and hairy and enhancer of split-1 (HES1, another notch signaling ligand) were measured using reverse transcription-polymerase chain reaction analysis. The results showed that proliferation of the WB-F344 cells was inhibited by matrine serum in a concentration- and time-dependent manner. Matrine serum downregulated Jagged 1 and HES1, and upregulated ALB, indicating the induction of WB-F344 cell differentiation. The effects of matrine serum were reversed by supplementing the culture medium with $0.1 \mathrm{~mol} / 1$ parathyroid hormone, a Notch signaling pathway activator. In conclusion, matrine induced
\end{abstract}

Correspondence to: Dr Zhiyun Yang, Department of Traditional Chinese Medicine, Beijing Ditan Hospital, Capital Medical University, 8 Jingshun East Street, Chaoyang, Beijing 100015, P.R. China

E-mail: zyyang66@sina.com

Key words: matrine serum, hepatic progenitor cells, differentiation, proliferation, Jagged 1/hairy and enhancer of split-1 signaling pathway hepatic differentiation of the hepatic progenitor cells, likely by inhibiting the Jagged 1/HES1 signaling pathway.

\section{Introduction}

Liver transplantation is the only efficacious clinical treatment available for end-stage liver disease, which can significantly increase rates of survival and improve quality of life. However a shortage of donors, high surgical costs and risks of immune rejection limit the application of liver transplantation, and novel alternative therapies are urgently required (1).

Previously, stem cell-based liver regeneration has been suggested as a potential technique in the treatment of end-stage liver disease. Several types of exogenous stem cells can be differentiated into hepatocytes, including induced pluripotent stem cells (2), embryonic stem cells (3), bone marrow mesenchymal stem cells (4) and hematopoietic stem cells. Therefore, these exogenous cells types may offer potential for use as seed cells for liver regeneration. In addition, candidate endogenous adult stem/progenitor cells can be recruited from the terminal bile ductules and activated, to proliferate and differentiate into hepatocytes and promote liver regeneration (5). The liver oval cells of the liver also possess stemness potential, which can give rise to hepatocytes and express the hepatocyte marker (6).

Various strategies have been investigated to induce hepatocyte differentiation in stem cells, including the use of growth factors (7) and hepatic stem cell niches (8), and there is increasing interest in the use of potential of traditional Chinese medicines to alter the proliferation and differentiation of stem cells. In previous years, the effects of several traditional Chinese medicines on stem cell behavior have been characterized. For example, $\beta$-Elemene, derived from Curcumae Radix, has been reported to inhibit angiogenesis by targeting Notch-1 in cancer stem-like cells (9). The Chinese herbal medicine, Yin-Chen-Hao-Tang, has also been implicated in the inhibition of fatty liver progression through increasing adiponectin and promoting endothelial progenitor cell survival (10).

Matrine, an alkaloid extracted from Sophora flavescens AIT, is reported to possess pharmacological properties, and has been found induce a series of therapeutic effects, including anti-fibrotic activity and the induction of cancer cell apoptosis (11). Matrine has been applied in the treatment of 
liver fibrosis (12) and it has been found to protect the liver from hepatic ischemia/reperfusion injury (13). In our previous study, it was demonstrated that the in vivo administration of matrine promoted oval cell-mediated liver regeneration through downregulation of the recombination signal-binding protein $(R B P)-J_{K}$ hairy and enhancer of split-1 (HES1) signaling pathway, suggesting that this compound may affect the differentiation of hepatic progenitor cells (14). The aim of the present study was to characterize the mechanisms underlying these previous observations. The present study aimed to investigate whether exposure to matrine serum can affect the proliferation and differentiation of hepatic progenitor cells in vitro, and to investigate the mechanism by which matrine affects the differentiation of hepatic progenitor cells, in order to provide novel insights regarding matrine-promoted liver regeneration in vivo.

\section{Materials and methods}

Reagents. Matrine (cat. no. 110805-200306) was purchased from the Chinese National Institute of Pharmaceutical and Biological Products (Beijing, China). Fetal bovine serum and RPMI 1640 medium were purchased from Gibco; Thermo Fisher Scientific, Inc., Waltham, MA, USA). Polyacrylamide, sodium dodecyl sulfate (SDS), 3-(4,5-dimethylthiazol-2-yl) -2,5-diphenyltetrazolium bromide (MTT) and L-glutamine were purchased from Sigma-Aldrich (St. Louis, MO, USA). TRIzol reagent was purchased from Invitrogen; Thermo Fisher Scientific, Inc.). Parathyroid hormone (PTH) was obtained from Bachem (Bubendorf, Switzerland), the $\mathrm{BCA}^{\mathrm{TM}}$ Protein Assay kit was purchased from Thermo Fisher Scientific, Inc. and the RNAprep pure Cell/Bacteria kit was purchased from Qiagen (Hilden, Germany). Antibodies against ALB, Jagged 1, HES1 and $\beta$-actin were obtained from Santa Cruz Biotechnology, Inc. (Danvers, MA, USA).

Preparation ofmatrine serum. A total of 40 male Sprague-Dawley rats weighing $\sim 300-400 \mathrm{~g}$ (age, 2.5 months) were obtained from the Animal Center of Chinese Academy of Medical Sciences (Beijing China). Rats were housed in an air-conditioned room under a $12 \mathrm{~h}$ light/dark cycle and had ad libitum access to water and food. The room temperature was $23-25^{\circ} \mathrm{C}$. These rats were divided into an experimental group and a control group, each containing 20 rats. The rats received esophageal infusion of either $2.5 \mathrm{~g} / 1$ matrine in physiological saline (experimental group) or physiological saline (control group) twice each day for 7 days. The matrine infusion was administered at a dose of $\sim 1 \mathrm{ml} / 100 \mathrm{~g}$. Subsequently, $1 \mathrm{~h}$ following the final infusion, blood from the inferior vena cava was collected and maintained at $4^{\circ} \mathrm{C}$ for $4 \mathrm{~h}$, following which the blood was centrifuged at $600 \mathrm{x} g$ for $10 \mathrm{~min}$ to obtain the matrine drug or control serum samples, which were sterilized by filtering through a $0.22 \mu \mathrm{m}$ millipore filtration membrane and stored at $-20^{\circ} \mathrm{C}$ for further use. The animal use and care protocol for the animal experiments in the present study was approved by the Institutional Animal Care and Use Committee of Capital Medical University (Beijing, China), and the study was approved by the ethics committee of Capital Medical University.

Cell culture and exposure to matrine serum. Rat hepatic progenitor cells (WB-F344) were purchased from the Drug
Research Institute, Chinese Academy of Medical Sciences, and were cultured in RPMI-1640 medium supplemented with $10 \%$ fetal bovine serum at $37^{\circ} \mathrm{C}$ in $5 \% \mathrm{CO}_{2}$. The WB-F344 medium was supplemented with 5, 10, 20 and 40\% serum from the rats administered with saline (negative control) or matrine (matrine serum) for 24 or $72 \mathrm{~h}$ at $37^{\circ} \mathrm{C}$, as indicated.

Evaluation of cell viability and inhibition. The WB-F344 cells were seeded into flat plates (Costar 3524; Corning Inc., Corning, $\mathrm{NY}, \mathrm{USA}$ ) at a density of $5 \times 10^{4} / \mathrm{cm}^{2}$ and the culture medium was supplemented with 5-40\% matrine serum. After $24 \mathrm{~h}$ at $37^{\circ} \mathrm{C}$, cell viability was determined using acridine orange/propidium iodide (AO/PI) staining (Sigma-Aldrich), using a standard protocol. After 24,48 and $72 \mathrm{~h}$ at $37^{\circ} \mathrm{C}$, the proliferation rates of the WB-F344 cells were evaluated using an MTT assay. Proliferation inhibition was calculated by comparison with cells incubated with culture medium only.

MTT assay. The WB-F344 cells were seeded into 96-well plates at a density of $2 \times 10^{4} / \mathrm{cm}^{2}$ and incubated overnight. The medium was replaced with fresh RPMI 1640 medium supplemented with 5,10 or $20 \%$ matrine serum. After 48 h, MTT $(5 \mathrm{mg} / \mathrm{ml}$; $20 \mathrm{ml}$ ) was added to each well. After $4 \mathrm{~h}$ at $37^{\circ} \mathrm{C}$, the medium was replaced with $150 \mathrm{ml}$ dimethyl sulfoxide and incubated for $20 \mathrm{~min}$. The optical density (OD) at $490 \mathrm{~nm}$ was measured

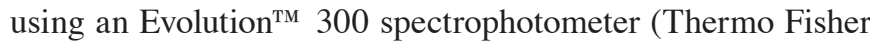
Scientific, Inc.). The inhibition ratio was calculated according to the following formula: Inhibition ratio $=(1-$ experimental OD) / control * $100 \%$. The experiments were repeated three times.

Reverse transcription-polymerase chain reaction (RT-PCR) analysis of the expression of Jagged 1, HESI and ALP. To determine the effects of matrine on the differentiation of WB-F344 cells, RNA was extracted from the cells following incubation in the presence or absence of 5, 10 and $20 \%$ matrine serum for 24 or $48 \mathrm{~h}$, and RT-PCR was performed to assess the expression levels of Jagged 1, HES1 and ALP. To further establish the mechanism of action, WB-F344 cells were incubated at a density of $2 \times 10^{4} / \mathrm{cm}^{2}$ in the presence or absence of $20 \%$ matrine serum for $48 \mathrm{~h}$, following which the cultures were supplemented with $0.1 \mathrm{~mol} / 1 \mathrm{PTH}$, an activator of the Notch signaling pathway, and incubated for a further $24 \mathrm{~h}$. The WB-F344 cells were collected and total RNA was extracted using an RNAprep Pure Cell/Bacteria kit (Tiangen Biotech Co., Ltd., Beijing China). Standard procedures were followed to obtain first-strand cDNA using a one-step RT-PCR kit (Qiagen GmbH, Hilden, Germany) according to the manufacturer's protocol. The total volume of the PCR reaction system was $20 \mu \mathrm{l}$, including $1 \mu \mathrm{l}$ cDNA sample, $1 \mu \mathrm{l}$ forward primers and $1 \mu \mathrm{l}$ reverse primers, $10 \mu \mathrm{l} 2 \mathrm{X}$ Power Taq PCR MasterMix (BioTeke Corporation, Beijing, China) and $7 \mu$ l double-distilled $\mathrm{H}_{2} \mathrm{O}$. The PCR cycling conditions were as follows: Initial denaturation at $94^{\circ} \mathrm{C}$ for $5 \mathrm{~min}$, followed by 25 cycles, which consisted of denaturation at $94^{\circ} \mathrm{C}$ for $30 \mathrm{sec}$, renaturation at $58^{\circ} \mathrm{C}$ for $30 \mathrm{sec}$ and annealing/extension at $72^{\circ} \mathrm{C}$ for $45 \mathrm{sec}$. The primers used were follows: JAGGED 1, forward 5'-ATGCGGTCCCCACGGACGCG-3' and reverse 5'-ACA CTCAGGACCCATCCAGC-3'; HES1, forward 5'-CAACAC GACACCGGACAAACC-3' and reverse 5'-AGTGCGCACCTC GGTGTTAAC-3'; $\beta$-actin, forward 5'-GCCATGTACGTAGCC 
ATCCA-3' and reverse 5'-GAACCGCTCATTGCCGATAG-3'. ALP, forward 5'-TGTCCCCAAAGAGTTTAAAGCTG-3' and reverse 5'-TCTTTATCTGCTTCTCCTTGTCTGG-3'. PCR products were detected by $2 \%$ agarose gel electrophoresis and were stained by ethidium bromide. The band intensity was quantified using ImageJ 1.48u software (National Institutes of Health, Bethesda, MD, USA). Signal intensity of the amplified product was normalized to its respective $\beta$-actin signal intensity.

Immunohistochemistry. The WB-F344 cells incubated in the presence or absence of $20 \%$ matrine serum for $48 \mathrm{~h}$ were fixed in $4 \%$ paraformaldehyde, and immunohistochemistry against Jagged1 and ALB was performed to examine the expression of ALB and Jagged 1 using conventional methods (15). The immunostained samples were observed using an Olympus BX51 microscope (Olympus Deutshland GmbH, Hamburg, Germany). Immunohistochemical staining was quantified with Image-Pro Plus 6.0 for Windows software (Media Cybernetics, Inc., Rockville, MD, USA) using its measurement function. The positively stained area was labeled and calculated according to the software guidelines. The intensity of immunostaining was expressed as positive cell area / total cell area x $100 \%$.

Western blotting. The WB-F344 cells incubated in the presence or absence of $20 \%$ matrine serum for $48 \mathrm{~h}$ were lysed using protein lysate buffer. Following the removal of debris through centrifugation at $12,000 \mathrm{x} \mathrm{g}$ for $20 \mathrm{~min}$ at $4^{\circ} \mathrm{C}$, the protein content was determined using a $\mathrm{BCA}^{\mathrm{TM}}$ Protein Assay kit (Thermo Fisher Scientific, Inc.). Total protein $(30 \mu \mathrm{g})$ was loaded onto $12 \%$ polyacrylamide-SDS gels and electrophoresed, followed by transfer onto polyvinylidene difluoride membranes under a constant electronic current of $300 \mathrm{~mA}$ for $2 \mathrm{~h}$. Following blocking in 5\% fat-free milk, the membranes were incubated with rabbit polyclonal anti-ALB (1:2,000; cat. no. sc-50536), goat polyclonal anti-Jagged 1 (1:2,000; cat. no. sc-34473) and rabbit polyclonal anti-HES1 (1:2,000; cat. no. sc-25392) antibodies at $4^{\circ} \mathrm{C}$ overnight, and were subsequently incubated with horseradish peroxidase-conjugated goat anti-rabbit and rabbit anti-goat immunoglobulin $\mathrm{G}$ secondary antibodies $(1: 10,000$; cat. nos. ZB-5301 and ZB-2306, respectively; ZSGB-Bio, Beijing, China) at room temperature for $1 \mathrm{~h}$. Protein separation was detected via enhanced chemiluminescence (Applygen Technologies, Inc., Beijing, China). The signals for ALB, Jagged 1 and HES1 were normalized to that of goat polyclonal anti- $\beta$-actin (1:2,000; cat. no. sc-1616).

Statistical analysis. All data are expressed as the mean \pm standard deviation of experiments repeated at least three times. Data were analyzed using SPSS 17.0 (SPSS, Inc., Chicago, IL, USA). The statistical significance of differences in quantitative data were analyzed using one-way analysis of variance and Student-Newman-Keuls test for multiple comparisons. $\mathrm{P}<0.05$ was considered to indicate a statistically significant difference.

\section{Results}

Effects of matrine treatment on the viability of WB-F344 hepatic progenitor cells. To determine the effects of matrine on the viability of hepatic progenitor cells in the present study, WB-F344 cells were incubated in medium supplemented with the serum of animals administered with saline or matrine (matrine serum) for $24 \mathrm{~h}$, and cell viability was measured using AO/PI staining. Supplementation of the culture medium with control serum or with 5-20\% matrine serum had no significant effect on the viability of the WB-F344 cells ( $P>0.05)$, however, when the culture medium contained $40 \%$ matrine serum, cell viability was reduced $(\mathrm{P}<0.05$; Fig. 1A and B). Therefore, only 5, 10 and $20 \%$ drug serum were used in the subsequent experiments.

Matrine inhibits the proliferation of WB-F344 cells. To evaluate the effect of matrine on the proliferation of WB-F344 cells, the present study measured the proliferation of WB-F344 cells incubated in the presence of absence of matrine serum for 24,48 and $72 \mathrm{~h}$ using an MTT assay. The inhibition of matrine serum inhibited the proliferation of the WB-F344 cells in a concentration- and time-dependent manner (Fig. 1C), whereas control serum had no effect on cell proliferation (data not shown).

Matrine promotes the hepatic differentiation of WB-F344 cells. The differentiation of WB-F344 hepatic progenitor cells into hepatic cells is characterized by the expression of ALB, a biomarker of mature hepatic cells. To evaluate the effect of matrine on the differentiation of hepatic progenitor cells, the transcription and distribution of ALB in WB-F344 cells incubated with 5-20\% matrine serum were determined using RT-PCR analysis. The transcription of ALB was enhanced by incubation with matrine serum in a time- and concentration-dependent manner (Fig. 2A).

In liver regeneration, several cell signaling pathways affect repair of the injured liver. Notch signaling has been implicated in the differentiation of stem cells (16). The present study used RT-PCR analysis to measure the expression levels of the Notch signaling pathway ligands, Jagged 1 and HES1, in WB-F344 cells incubated with matrine serum. The results demonstrated concentration- and time-dependent reductions in the expression levels of Jagged 1 and HES1 (Fig. 2A and B).

To further evaluate the effects of matrine on hepatic progenitor cell differentiation, the present study used immunohistochemistry to assess the levels of ALB and Jagged 1 in the WB-F344 cells incubated with matrine serum. The results revealed that incubation with $20 \%$ matrine serum significantly increased the content of ALB in the cytoplasm and plasma membrane, and reduced the content of Jagged 1 (Fig. 3A and B; $\mathrm{P}<0.01)$. The western blotting confirmed these observed differences in the contents of ALB, Jagged 1 and HES1 in the WB-F344 incubated with matrine serum. A $20 \%$ concentration of matrine serum significantly promoted the accumulation of ALB, and reduced the accumulation of Jagged 1 (Fig. 3C; $\mathrm{P}<0.01)$. These results suggested that matrine promoted the differentiation of WB-F344 cells and downregulated the Notch signaling pathway.

Matrine promotes the hepatic differentiation of WB-F344 cells by inhibiting the Notch signaling pathway. To further investigate whether the Notch signaling pathway was involved in the hepatic differentiation of WB-F344 cells induced by matrine, the present study pre-treated the WB-F344 cells with $20 \%$ matrine serum, and then supplemented the medium with PTH, which is an activator of the Notch signaling pathway (17). The 


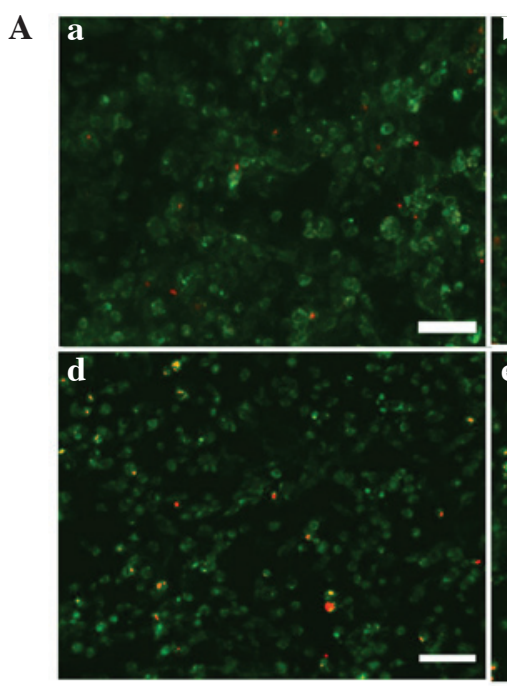

B

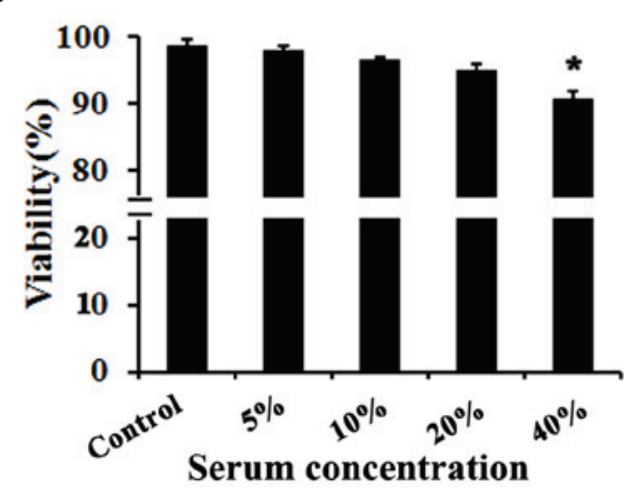

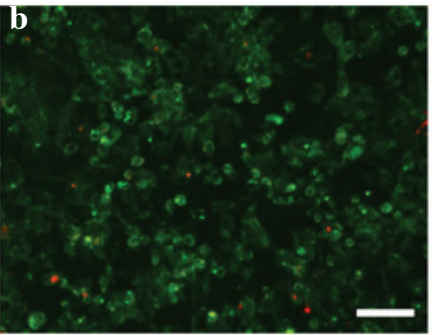
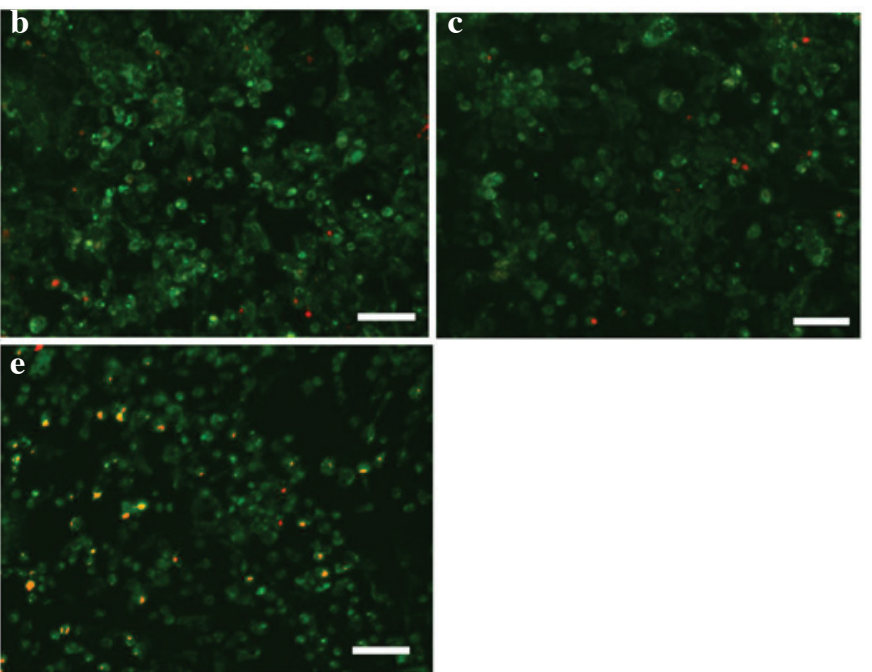

C

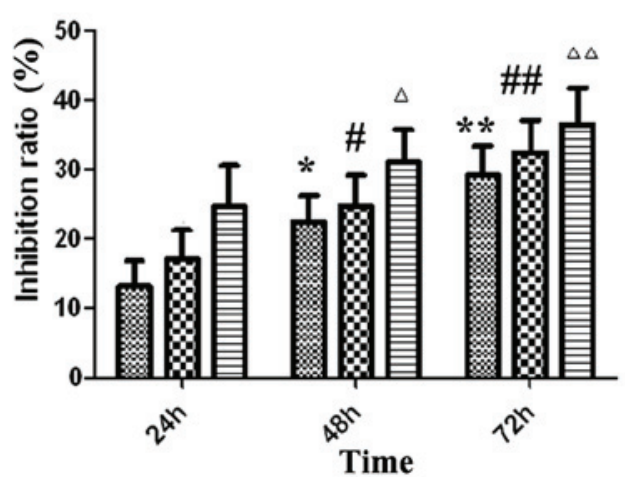

$5 \% \infty 10 \%$ 무

Figure 1. Viability and growth of WB-F344 exposed to matrine serum. (A) Viability of WB-F344 cells incubated in the presence or absence of matrine serum for $24 \mathrm{~h}$, evaluated using acridine orange/propidium iodide staining. (a) Control; (b) 5\% matrine serum; (c) 10\% matrine serum; (d) 20\% matrine serum; (e) $40 \%$ matrine serum (scale bar=100 $\mu \mathrm{m}$ ). (B) Quantification of WB-F344 cell viability ${ }^{*} \mathrm{P}<0.05$, compared with the other groups. (C) Inhibition of WB-F344 proliferation, assessed using a 3-(4,5-dimethylthiazol-2-yl) -2,5-diphenyltetrazolium bromide assay following incubation in the presence or absence of matrine serum for $24-72 \mathrm{~h}$. ${ }^{*} \mathrm{P}<0.05$ and ${ }^{* *} \mathrm{P}<0.01$ for $5 \%$ group, vs. $24 \mathrm{~h} ;{ }^{*} \mathrm{P}<0.05$ and ${ }^{\# \#} \mathrm{P}<0.01$ for $10 \%$ group, vs. $24 \mathrm{~h} ;{ }^{{ }^{*} \mathrm{P}<0.05 \text { and }}{ }^{\Delta \Delta} \mathrm{P}<0.01$ for $20 \%$ group, vs. $24 \mathrm{~h}$.

A
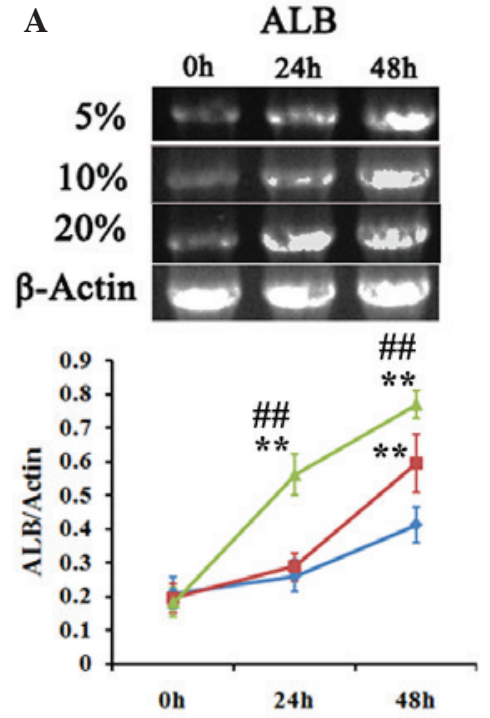

B
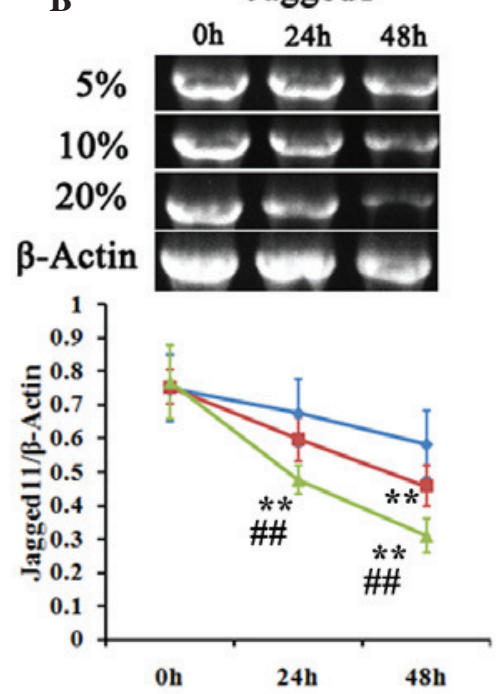
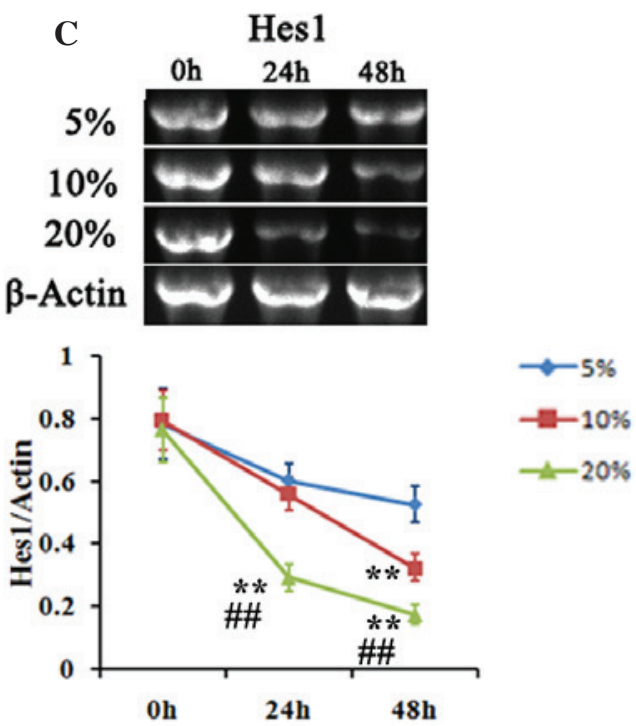

Figure 2. Transcription of ALB, Jagged 1 and HES1 in WB-F344 cells exposed to matrine serum. The expression levels of ALB, Jagged 1 and HES1 in WB-F344 cells incubated with matrine serum for 24 or $48 \mathrm{~h}$ were assessed using reverse transcription-polymerase chain reaction analysis. (A) Transcription of ALB was enhanced and the expression levels of (B) Jagged 1 and (C) HES1 were reduced following incubation with matrine serum in a concentration- and time-dependent manner. Data are presented as the mean \pm standard deviation. ALB, albumin; HES1, hairy and enhancer of split $1 .{ }^{* *} \mathrm{P}<0.01$ compared with $5 \%$ group; ${ }^{\# \#} \mathrm{P}<0.01$ compared with $10 \%$ group. 


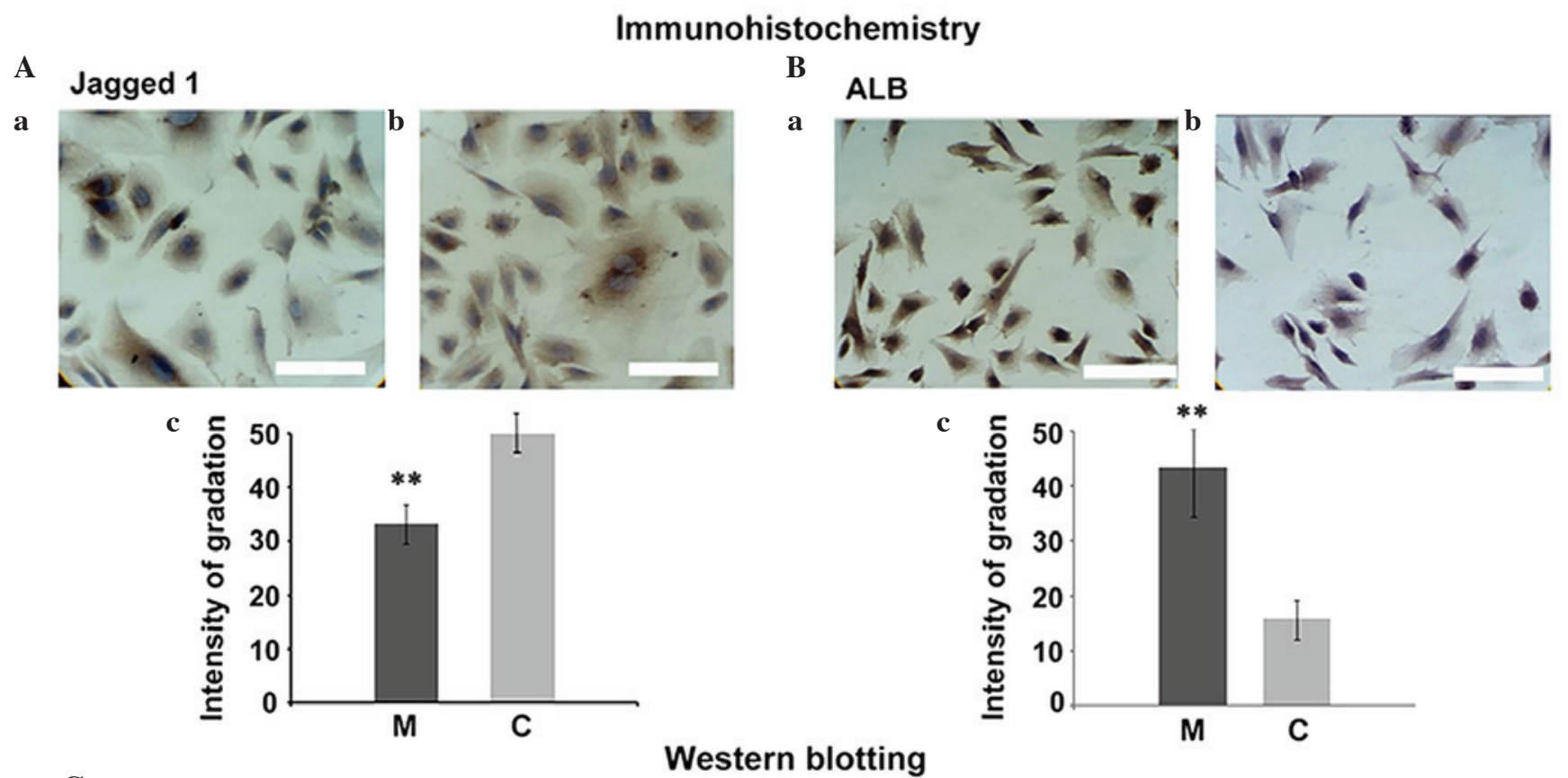

C
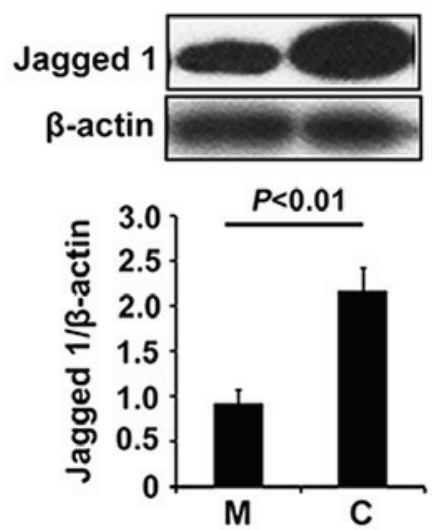

Western blotting
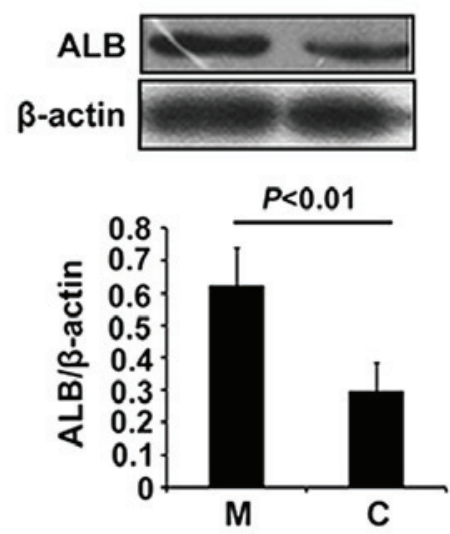
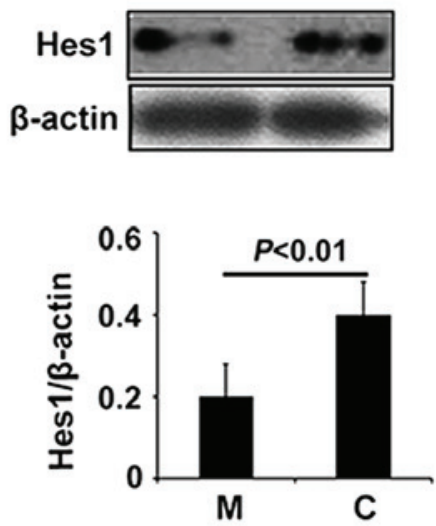

Figure 3. Contents of ALB, Jagged 1 and HES1 in WB-F344 cells exposed to matrine serum. The content of (A) ALB and (B) Jagged 1 in WB-F344 cells incubated in the (a) absence or (b) presence of $20 \%$ matrine serum for $48 \mathrm{~h}$ were assessed using immunihistochemical staining (scake bar $=50 \mu \mathrm{m}$ ). (c) Immunohistochemical staining was quantified using IPWIN60 software. Data are presented as the mean \pm standard deviation. ${ }^{* *} \mathrm{P}<0.01$. (C) Content of ALB, Jagged 1 and HES1 in WB-F344 cells incubated in the presence or absence of $20 \%$ matrine serum, assessed using western blotting and quantified using IPWIN60 software. M, matrine; C, control; ALB, albumin; HES1, hairy and enhancer of split 1.

transcription levels of Jagged 1 and HES1 were then determined using RT-PCR analysis. It was observed that the addition of $0.1 \mathrm{~mol} / \mathrm{l} \mathrm{PTH}$ ameliorated the changes in the expression levels of Jagged 1, ALB and HES1 induced by matrine (Fig. 4). The expression levels of Jagged 1, ALB and HES1 in the WB-F344 cells simultaneously exposed to matrine serum and PTH were comparable with those in the control group $(\mathrm{P}>0.05)$.

The promotion of Notch by PTH likely enhanced the transcription of Jagged 1 and HES1 in WB-F344 exposed to matrine, and was accompanied with a significant decrease in the expression of ALB $(\mathrm{P}<0.01)$. These results provided further support for the hypothesis that matrine promotes the hepatic differentiation of WB-F344 by inhibiting the Notch signaling pathway.

\section{Discussion}

Our previous study demonstrated that the administration of the traditional Chinese medicine, matrine, promotes oval cell-mediated liver regeneration, suggesting that this compound affected hepatic progenitor cell differentiation (14). In the present study, the effect of matrine on the differentiation of the WB-F344 rat hepatic progenitor cell line were investigated. It was found that matrine affected the proliferation and hepatic differentiation of the WB-F344 cells in a concentration- and time-dependent manner. It was demonstrated that matrine inhibited the expression of the notch signaling ligands, Jagged 1 and HES1, in the WB-F344, and induced the expression of ALB, a biomarker of mature hepatocytes. Furthermore, the exogenous activation of notch signaling by PTH prevented the effects of matrine, reducing the expression of ALB, and recovering the expression of Jagged 1 and HES1.

Matrine, a compound extracted from Sophora flavescens Ait, has been used as clinically in China for a wide range of conditions, particularly in protecting the liver and inhibiting cancer, and matrine has been reported to reduce inflammation, viral replication and fibrosis $(11-14,18)$. It has also been 

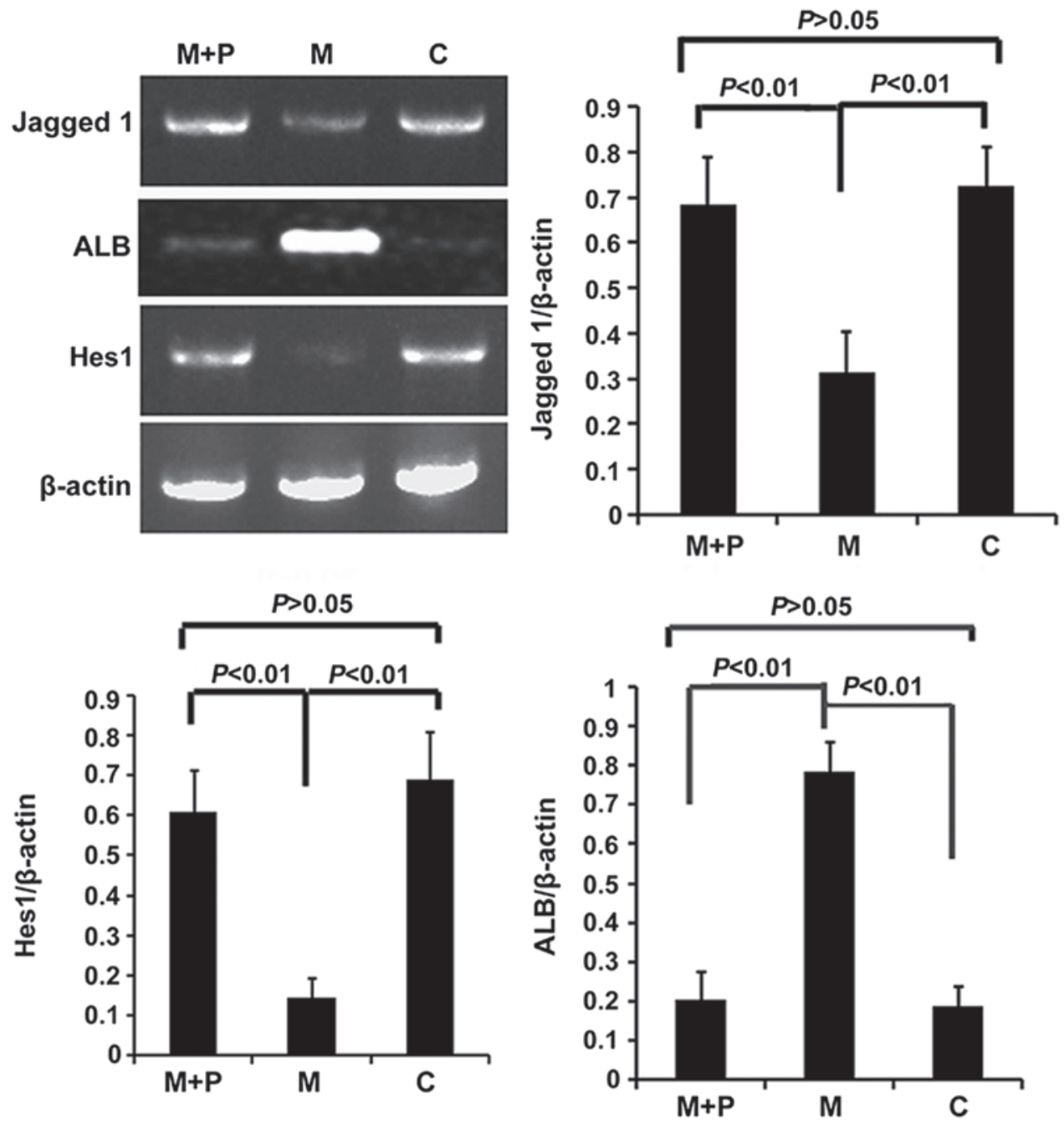

Figure 4. Expression levels of ALB, Jagged 1 and HES1 in WB-F344 cells incubated with PTH and matrine. The expression levels of ALB, Jagged 1 and HES1 in WB-F344 cells incubated with $0.1 \mathrm{~mol} / 1 \mathrm{PTH}$ and $20 \%$ matrine serum for $48 \mathrm{~h}$ were assessed using reverse transcription-polymerase chain reaction. The addition of PTH ameliorated the changes in the transcription of ALB, Jagged 1 and HES1 observed following incubation with matrine serum. Data are presented as the mean \pm standard deviation. ALB, albumin; HES1, hairy and enhancer of split 1; PTH, parathyroid hormone; M, matrine; C, control; M+P, matrine serum $+\mathrm{PTH}$.

reported that matrine can reduce the severity of acute liver injury through its anti-inflammatory and anti-oxidative activities (13). Matrine has also been reported to modulate signaling pathways to inhibit the proliferation and promote the apoptosis of hepatoma cells (18).

The present study reported for the first time, to the best of out knowledge, that matrine can affect the proliferation and differentiation of hepatoma stem cells. When the liver is severely injured, hepatocytes may be lost through apoptosis, necrosis or reduced proliferation. Previous investigations have suggested that a hepatic progenitor cell population of oval cells are recruited to repair the damaged liver (19). Hepatic oval cells are considered to represent a stem-like cell lineage, originating from the intrahepatic bile ducts or bone marrow cells $(20,21)$. In a rat model of partial hepatectomy, oval cells were recruited for involvement in liver regeneration. Therefore, oval cells may represent good candidate seeding cells for liver tissue engineering.

Liver regeneration is markedly affected by the local hepatic microenvironment, which is composed of non-parenchymal cells, the extracellular matrix and growth factors, which act through paracrine or autocrine pathways to modulate the proliferation and differentiation of oval cells $(22,23)$. This is mediated intracellularly through the phosphoinositide 3-kinase/AKT-nuclear factor- $\kappa \mathrm{B}$ signaling pathways $(24,25)$.

The Notch signaling pathway is a highly conserved signal transduction pathway, which is essential for the differentiation and proliferation of stem cells (26). In mammals, notch receptors, ligands, including Jagged 1 and RBP-Jk/CBF1 in the nucleus, and downstream target genes, including HES1, have been implicated in the regulation of stem cell differentiation and proliferation (27). Activation of Notch signaling is reported to restrict oligodendrocyte differentiation and promoteastrogliogenesis (28). Notch signaling has been implicated in mammary stem cell and luminal cell commitment, and activation of Notch enhances self-renewal and transformation (29). In liver development, Notch has been reported to regulate liver stem cell differentiation into hepatocytes (30). In the present study, it was observed that high levels of Jagged 1 and HES1 may favor self-renewal of WB-F344 cells. Exposure to matrine inhibited the expression of Jagged 1 and HES1, and 
promoted the expression of ALB, a biomarker of mature hepatocytes. Furthermore, the effects of matrine were ameliorated by the addition of PTH, an activator of the Notch signaling pathway. These results indicated that matrine can stimulate the differentiation of WB-F344 into hepatocytes through inhibition of the Notch-Jagged 1-HES1 signaling pathway.

The present study represents the first report, to the best of our knowledge, of the effects of matrine on the hepatic differentiation of WB-F344 cells. The present study demonstrated that matrine likely induced the hepatic differentiation of WB-F344 cells through a mechanism involving downregulation of the Notch-Jagged 1-HES1 signaling pathway. The precise molecular mechanisms underlying the effect of matrine on the Notch-Jagged 1-HES1 pathway remain to be elucidated, however, the present study highlights an important physiological component of stem cell differentiation, and suggest that matrine may be important in the stimulation of hepatic stem cell differentiation.

\section{Acknowledgements}

This study was supported by the National Natural Science Foundation of China (grant no. 30873423), the Beijing Natural Science Foundation of China (grant no. 142081) and the Capital Health Research and Development of Special (grant no. 2016-271-21).

\section{References}

1. Zhu Y, Miao Z, Gong L and Chen W: Transplantation of mesenchymal stem cells expressing TIMP-1-shRNA improves hepatic fibrosis in $\mathrm{CCl}_{4}$-treated rats. Int J Clin Exp Pathol 8: 8912-8920, 2015.

2. Tessier S, Karczewski P, Krause EG, Pansard Y, Acar C, Lang-Lazdunski M, Mercadier JJ and Hatem SN: Regulation of the transient outward $\mathrm{K}(+)$ current by $\mathrm{Ca}(2+) /$ calmodulin-dependent protein kinases II in human atrial myocytes. Circ Res 85: 810-819, 1999.

3. Bodart V,Bouchard JF, McNicoll N, EscherE, Carrière P, GhigoE, Sejlitz T, Sirois MG, Lamontagne D and Ong H: Identification and characterization of a new growth hormone-releasing peptide receptor in the heart. Circ Res 85: 796-802, 1999.

4. Knight B, Akhurst B, Matthews VB, Ruddell RG, Ramm GA, Abraham LJ, Olynyk JK and Yeoh GC: Attenuated liver progenitor (oval) cell and fibrogenic responses to the choline deficient, ethionine supplemented diet in the BALB/c inbred strain of mice. J Hepatol 46: 134-141, 2007.

5. Roskams TA, Theise ND, Balabaud C, Bhagat G, Bhathal PS, Bioulac-Sage P, Brunt EM, Crawford JM, Crosby HA, Desmet V, et al: Nomenclature of the finer branches of the biliary tree: Canals, ductules, and ductular reactions in human livers. Hepatology 39: 1739-1745, 2004.

6. Duncan AW, Dorrell C and Grompe M: Stem cells and liver regeneration. Gastroenterology 137: 466-481, 2009.

7. Newsome PN, Hussain MA and Theise ND: Hepatic oval cells: Helping redefine a paradigm in stem cell biology. Curr Top Dev Biol 61: 1-28, 2004.

8. Tanimizu N, Tsujimura T, Takahide K, Kodama T, Nakamura K and Miyajima A: Expression of Dlk/Pref-1 defines a subpopulation in the oval cell compartment of rat liver. Gene Expr Patterns 5: 209-218, 2004.

9. Yano Y, Hayashi Y, Teramoto T, Nakaji M, Nagy P, Ninomiya T, Wada A, Hirai M, Kim SR, Seo Y, et al: Apoptotic pathway related to oval cell proliferation. J Gastroenterol Hepatol 19: 866-872, 2004

10. Lee TY, Chang HH, Lo WC and Lin HC: Alleviation of hepatic oxidative stress by Chinese herbal medicine Yin-Chen-Hao-Tang in obese mice with steatosis. Int J Mol Med 25: 837-844, 2010.
11. Liu T, Song Y, Chen H, Pan S and Sun X: Matrine inhibits proliferation and induces apoptosis of pancreatic cancer cells in vitro and in vivo. Biol Pharm Bull 33: 1740-1745, 2010.

12. Gao HY, Li GY, Lou MM, Li XY, Wei XY and Wang JH: Hepatoprotective effect of Matrine salvianolic acid B salt on carbon tetrachloride-induced hepatic fibrosis. J Inflamm (Lond) 9: 16, 2012

13. Zhang F, Wang X, Tong L, Qiao H, Li X, You L, Jiang H and Sun X: Matrine attenuates endotoxin-induced acute liver injury after hepatic ischemia/reperfusion in rats. Surg Today 41: 1075-1084, 2011

14. Yang ZY, Wang L, Hou YX and Wang XB: Effects of matrine on oval cell-mediated liver regeneration and expression of RBP- $\mathrm{J}_{\mathrm{K}}$ and HES1. Mol Med Rep 7: 1533-1538, 2013.

15. Jubb AM, Browning L, Campo L, Turley H, Steers G, Thurston G, Harris AL and Ansorge O: Expression of vascular Notch ligands Delta-like 4 and Jagged-1 in glioblastoma. Histopathology 60: 740-747, 2012.

16. Calvi LM, Adams GB, Weibrecht KW, Weber JM, Olson DP, Knight MC, Martin RP, Schipani E, Divieti P, Bringhurst FR, et al: Osteoblastic cells regulate the haematopoietic stem cell niche. Nature 425: 841-846, 2003.

17. Ke Z, Mao X, Li S, Wang R, Wang L and Zhao G: Dynamic expression characteristics of Notch signal in bone marrow-derived mesenchymal stem cells during the process of differentiation into hepatocytes. Tissue Cell 45: 95-100, 2013.

18. Zhang JQ, Li YM, Liu T, He WT, Chen YT, Chen XH, Li X, Zhou WC, Yi JF and Ren ZJ: Antitumor effect of matrine in human hepatoma G2 cells by inducing apoptosis and autophagy. World J Gastroenterol 16: 4281-4290, 2010.

19. Assimakopoulos SF, Tsamandas AC, Alexandris IH, Georgiou C, Vagianos CE and Scopa CD: Stimulation of oval cell and hepatocyte proliferation by exogenous bombesin and neurotensin in partially hepatectomized rats. World J Gastrointest Pathophysiol 2: 146-154, 2011.

20. Lowes KN, Croager EJ, Olynyk JK, Abraham LJ and Yeoh GC: Oval cell-mediated liver regeneration: Role of cytokines and growth factors. J Gastroenterol Hepatol 18: 4-12, 2003.

21. Oh SH, Witek RP, Bae SH, Zheng D, Jung Y, Piscaglia AC and Petersen BE: Bone marrow-derived hepatic oval cells differentiate into hepatocytes in 2-acetylaminofluorene/partial hepatectomy-induced liver regeneration. Gastroenterology 132: 1077-1087, 2007.

22. Mavier P, Martin N, Couchie D, Préaux AM, Laperche Y and Zafrani ES: Expression of stromal cell-derived factor-1 and of its receptor CXCR4 in liver regeneration from oval cells in rat. Am J Pathol 165: 1969-1977, 2004.

23. Zhang W, Chen XP, Zhang WG, Zhang F, Xiang S, Dong HH and Zhang L: Hepatic non-parenchymal cells and extracellular matrix participate in oval cell-mediated liver regeneration. World J Gastroenterol 15: 552-560, 2009.

24. Malato Y, Ehedego H, Al-Masaoudi M, Cubero FJ, Bornemann J, Gassler N, Liedtke C, Beraza N and Trautwein C: NF- $\kappa$ B essential modifier is required for hepatocyte proliferation and the oval cell reaction after partial hepatectomy in mice. Gastroenterology 143: 1597-1608. e11, 2012.

25. Okano J, Shiota G, Matsumoto K, Yasui S, Kurimasa A, Hisatome I, Steinberg P and Murawaki Y: Hepatocyte growth factor exerts a proliferative effect on oval cells through the PI3 K/AKT signaling pathway. Biochem Biophys Res Commun 309: 298-304, 2003.

26. Chiba S: Notch signaling in stem cell systems. Stem Cells 24: 2437-2447, 2006.

27. Ge W, Martinowich K, Wu X, He F, Miyamoto A, Fan G, Weinmaster G and Sun YE: Notch signaling promotes astrogliogenesis via direct CSL-mediated glial gene activation. J Neurosci Res 69: 848-860, 2002.

28. Wang S, Sdrulla AD, diSibio G, Bush G, Nofziger D, Hicks C, Weinmaster $\mathrm{G}$ and Barres BA: Notch receptor activation inhibits oligodendrocyte differentiation. Neuron 21: 63-75, 1998.

29. Bouras T, Pal B, Vaillant F, Harburg G, Asselin-Labat ML, Oakes SR, Lindeman GJ and Visvader JE: Notch signaling regulates mammary stem cell function and luminal cell-fate commitment. Cell Stem Cell 3: 429-441, 2008.

30. Wang T, You N, Tao K, Wang X, Zhao G, Xia N, Li N, Tang L, Liu W and Dou K: Notch is the key factor in the process of fetal liver stem/progenitor cells differentiation into hepatocytes. Dev Growth Differ 54: 605-617, 2012. 